\title{
CORRECTION
}

\section{Deconstructing the diagnostic reasoning of human versus artificial intelligence}

CMAJ has been made aware of an error that occurred in the Dec. 2, 2019, issue. ${ }^{1}$

In the first paragraph of the section "How do humans and Al perform diagnostic tasks and learn to make diagnoses?", the last sentence read, "A physician solves most clinical problems in an intuitive and deductive way, whereas Al problem-solving depends on access to and analytical and deductive processing of large quantities of data that relate to the case." It should have read, "A physician solves most clinical problems in an intuitive and deductive way, whereas $\mathrm{Al}$ problem-solving depends on access to and analytical and inductive processing of large quantities of data that relate to the case."

This has been corrected at cmaj.ca.

Cite as: CMAJ 2020 January 6;192:E17. doi: 10.1503/cmaj.191634

\section{Reference}

1. Pelaccia T, Forestier G, Wemmert C. Deconstructing the diagnostic reasoning of human versus artificial intelligence. CMAJ 2019;191:E1332-5. 